$16^{\text {th }}$ International Conference on

AEROSPACE SCIENCES \& AVIATION TECHNOLOGY,

ASAT - 16 - May 26 - 28, 2015, E-Mail: asat@ mtc.edu.eg

Military Technical College, Kobry Elkobbah, Cairo, Egypt

Tel : +(202) 24025292 - 24036138, Fax: +(202) 22621908

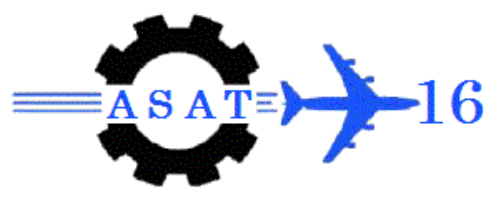

\title{
Investigation of Slow-Active Suspension System's Non-linearity on The Performance of The Anti-lock Brake System
}

\author{
A. M. Onsy ${ }^{*}$, A. M. Sharaf ${ }^{\dagger}$, M. M. Ashry ${ }^{\star}$ and S. M. El-demerdash ${ }^{\S}$
}

\begin{abstract}
This paper presents an advanced integrated controller design for military vehicle slow-active suspension system and anti-lock brake system (ABS) considering the effect of the suspension components non-linearity on the braking dynamics. The presented investigation is applied to a quarter vehicle model using the Magic Formula tire model and the actual characteristics for suspension damper (throttle valve) and spring (gas spring). The suspension controller is designed based on LQR using a linearized vehicle model and the ABS controller is designed based on ON/OF control methodology using tire skid ratio of $15 \%$ as a reference value. The mathematical derivations as well as the control techniques are numerically implemented in MATLAB environment. Several simulation results are carried out considering typical performance measures such as stopping time, stopping distance and vehicle body vertical acceleration. The results illustrated that, the integrated controller reduces the stopping distance on different road surfaces and therefore improves the braking performance to avoid or reduce the impact of vehicle accident.
\end{abstract}

Keywords: Slow-active suspension, Anti-lock braking system, Vehicle dynamics and control.

\section{Nomenclatures}

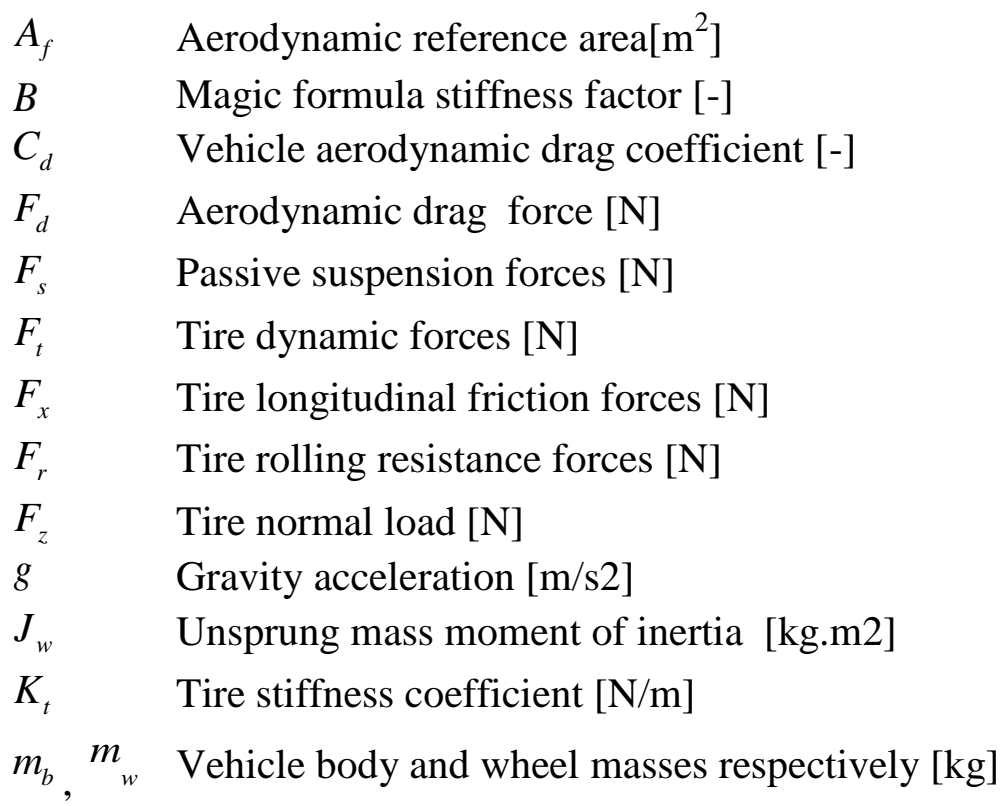

\footnotetext{
* PhD Student, Automotive Engineering Dept., Military Technical College

${ }^{\dagger}$ Associate Professor, Head of Automotive Engineering Dept., Military Technical College

* Associate Professor, Optoelectronics Dept., Military Technical College, Cairo, Egypt

${ }^{\S}$ Professor, Helwan University, Faculty of Engineering and Technology, Mataria, Cairo, Egypt
} 


$\begin{array}{ll}P_{a}, P_{d} & \text { Actual and demand brake pressures respectively }\left[\mathrm{N} / \mathrm{m}^{2}\right] \\ R_{w} & \text { Tire dynamic radius }[\mathrm{m}] \\ V & \text { Vehicle forward speed }[\mathrm{m} / \mathrm{s}] \\ \ddot{x}_{b} & \text { Vehicle braking deceleration }\left[\mathrm{m} / \mathrm{s}^{2}\right] \\ z_{o} & \text { Road displacement }[\mathrm{m}] \\ z_{b}, z_{w} & \text { Sprung mass and unsprung mass vertical displacements }[\mathrm{m}] \\ \mu_{b} & \text { Disk brake coefficient of friction [-] }\end{array}$

\section{Introduction}

The military vehicles are regularly working on different terrains and thus needs high stability and safety during all operating conditions $[1,2]$. The active suspension systems and anti-lock brake systems (ABS) are the vehicle chassis controllable systems which affect vehicle dynamics, stability and safety. Much research has been carried out to design different active suspensions as well as ABS systems using different control theories to improve the ride comfort and braking performance [2-12]. The controllers of these chassis controllable systems are designed based on an individual manner ignoring their interaction in practice. Recently [13-15], more attention is given to design an integrated controller for the so called slow-active suspension and ABS systems considering the dynamic coupling between them through the tire/road interaction forces.

The motivation of the presented research arises from the fact that, the tire forces in longitudinal direction - either due to traction or braking - are fundamentally regulated by the available adhesion potential at the tire-ground contact patch. This potential is dependent upon the road friction $(\mu)$ and the tire imposed vertical force. Sequentially, this tire vertical force is predominantly restricted by its vertical oscillation which is highly controlled by the properties of the suspension system. The presented paper exploits the aforementioned philosophy in favor of both ride and braking dynamics.

The details of the modelling basis are reported by the authors in [14] including an integrated control system of anti-lock brake system (ABS) and linearized slow-active suspension system. A linear optimization technique was followed to improve the ride dynamics in terms of suspension working space, body vertical acceleration and tire dynamic normal load.

In this paper, the reported initial approach is extended by inclusion of non-linear slow-active controlled suspension system characteristics. Additionally, the controller is designed based on the optimal control theory; taking into account changes in vehicle speed during the braking process. The suspension controller feedback gains are selected to minimize variations in tireroad normal forces. The system optimization based on the linear optimal control theory is carried out only for the linear system and the calculated feedback gains are used in both linear and non-linear cases. The ABS controller is designed to control the skid ratio by a proportional directional valve with a time delay of $0.1 \mathrm{sec}$. 


\section{Non-Linear Suspension System Model}

\subsection{Equations of Motion:}

A quarter vehicle model is employed to correlate the vehicle ride dynamics due to vertical oscillations and the vehicle performance in the longitudinal direction due to the application of brakes as depicted in Fig. 1. The model consists of an unsprung or wheel mass $\left(m_{w}\right)$, which is connected to approximately a quarter of the vehicle's sprung mass $\left(m_{b}\right)$ by a single acting hydraulic cylinder.

The hydro-pneumatic suspension system consists of gas spring which is equivalent to mechanical spring and flow control valve (throttle valve) which is equivalent to damper. The ride model possesses two degrees of freedom in vertical direction namely; the vertical displacement of the vehicle quarter body sprung mass $\left(z_{b}\right)$ and the vertical displacement of the wheel center $\left(z_{w}\right)$. Considering the Newton second law, the equations of motion are written as follows:

$$
\begin{aligned}
& m_{w} \cdot \ddot{z}_{w}=\underbrace{k_{t} \cdot\left(z_{O}-z_{w}\right)}_{\text {Tire Force }}-F_{S} \\
& m_{b} \cdot \ddot{z}_{b}=F_{S}
\end{aligned}
$$

With the hydro-pneumatic based systems, active control is exercised by regulating the volume of oil which flows into or out of the strut. This system uses a low bandwidth proportional directional control valve. The fluid pressure is generated by a hydraulic pump with accumulators providing transient flow requirements above the average. For a slow-active suspension system, the suspension force $\left(F_{S}\right)$ is calculated as follows:

$$
F_{S}=A_{s t} \cdot P_{s}^{\prime}
$$

Where $\left(A_{s t}\right)$ is the area of the piston strut given by: $\left(A_{s t}=\pi \cdot R_{s t}{ }^{2}\right),\left(R_{s t}\right)$ is the strut piston radius. The strut perturbation pressure $\left(P_{s}^{\prime}\right)$ is equal to gas spring perturbation pressure $\left(P_{g}^{\prime}\right)$ in addition to the pressure drop across the throttle valve (damping element) $\left(\Delta P_{d}\right)$.

$$
P_{s}^{\prime}=P_{g}^{\prime}+\Delta P_{d}
$$

Additionally, the dependency of the pressure drop across the throttle valve $\left(\Delta P_{d}\right)$ on the flow rate through the throttle valve $\left(Q_{D}\right)$ considering different constants for throttle valve $\left(C_{1}\right)$ are depicted in Fig 2. and can be mathematically represented as follows:

$$
\Delta P_{d}=C_{1} \cdot Q_{D}^{2}
$$

Assuming an incompressible fluid flow, the rate of change of the fluid volume $\left(Q_{D}\right)$ can be expressed in terms of suspension relative velocity between the vehicle body and wheel $\left(\dot{z}_{w}-\dot{z}_{b}\right)$ :

$$
Q_{D}=A_{s t} \cdot\left(\dot{z}_{w}-\dot{z}_{b}\right)
$$




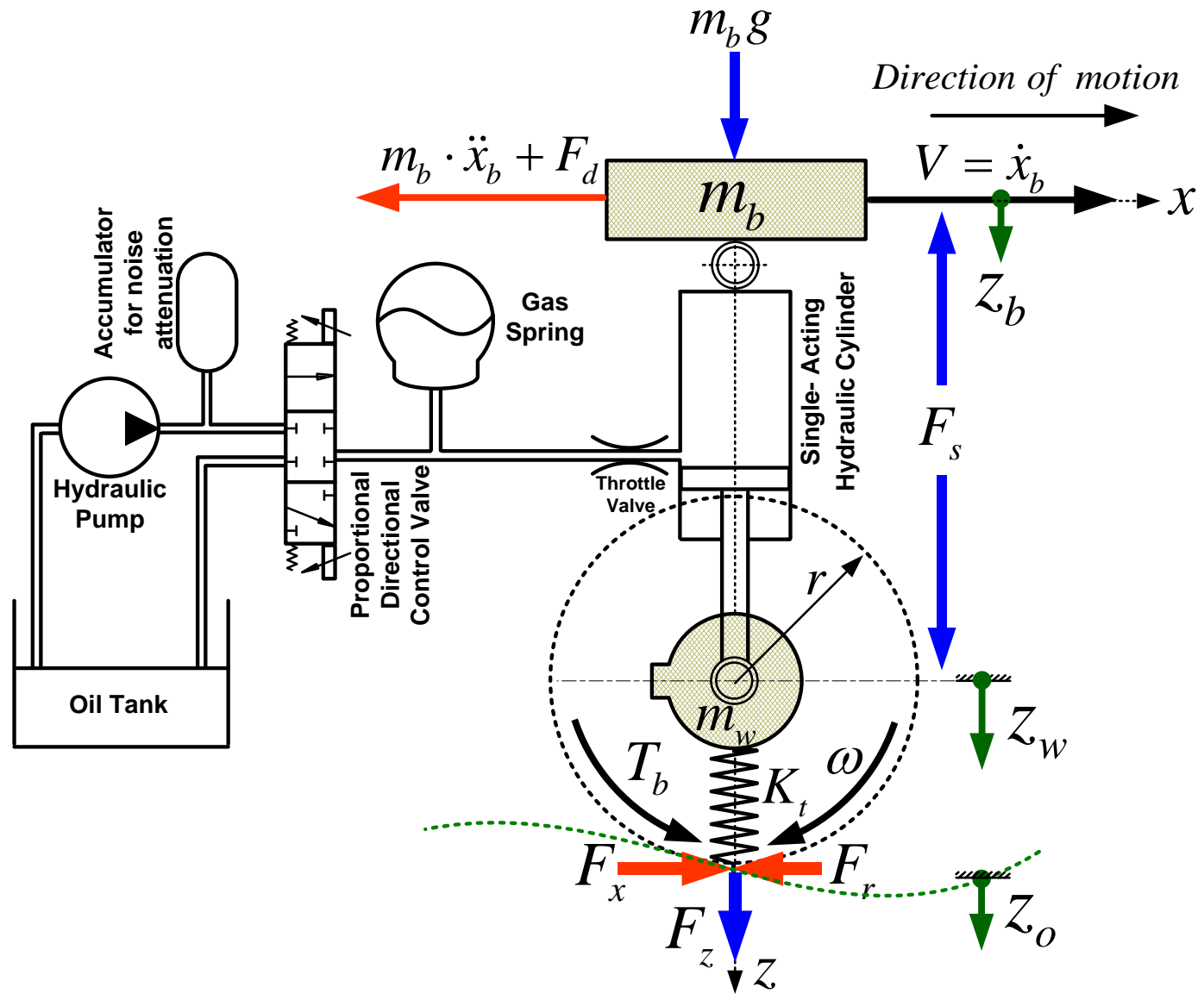

Fig. 1.Representation of the Quarter Vehicle Model of the IntegratedSystem

\subsection{The Flow Control Valve}

The non-linear characteristics of the flow control or throttle valve used in this paper is based on a typical valve type DV20-1-10/M which is produced by REXROTH Ltd [6]. The valve characteristics for different throttling positions is shown in Fig 2.

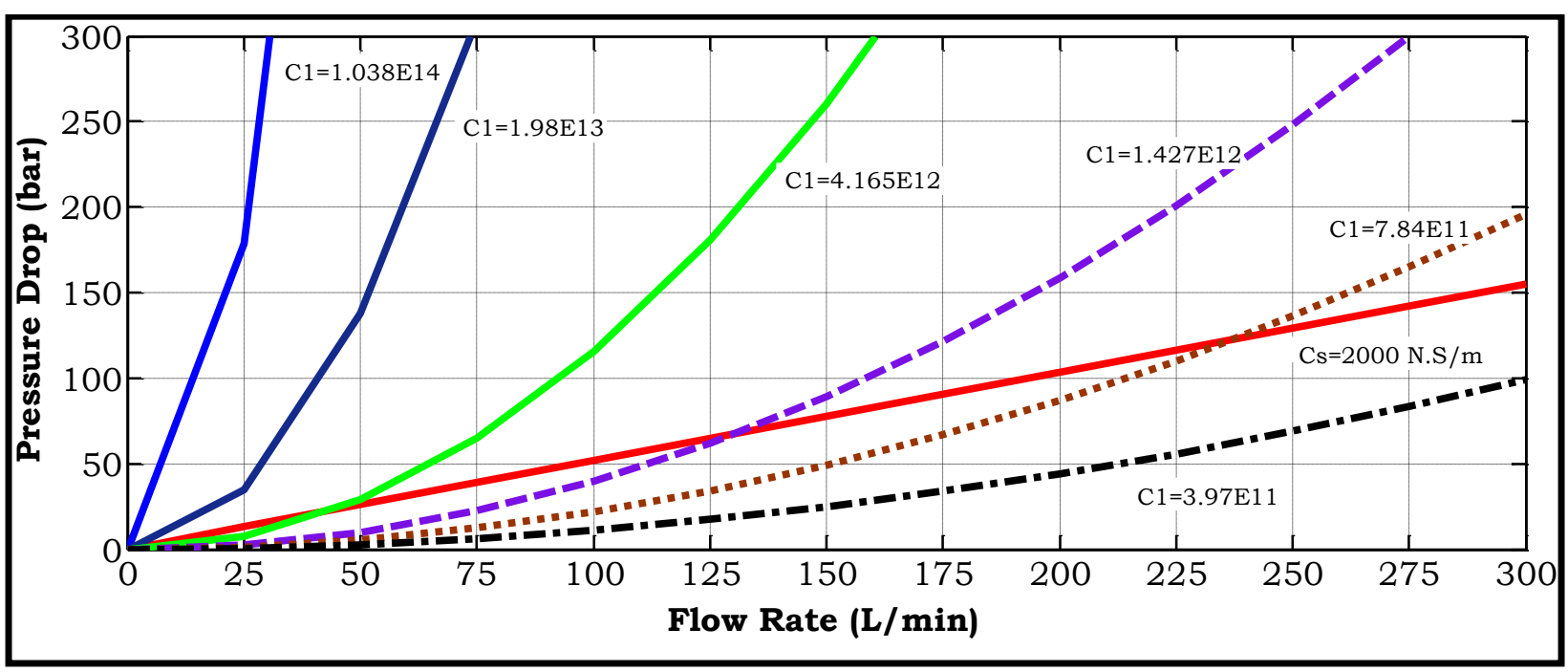

Fig. 2.Non-linear Characteristics of the Flow Control Throttle Valve 


\subsection{The Gas Spring}

The gas spring static pressure $\left(P_{g s t}\right)$ and gas spring static volume $\left(V_{g s t}\right)$ are set according the quarter body mass $\left(m_{b}\right)$ to be supported and suspension stiffness $\left(K_{\text {susp }}\right)$ and are given by:

$$
\begin{aligned}
P_{g s t} & =\frac{m_{b} \cdot g}{A_{s t}} \\
V_{g s t} & =\frac{A_{s t}^{2} \cdot \gamma \cdot P_{g s t}}{K_{s u s p}}
\end{aligned}
$$

Due to the large variation in the strut pressure from static equilibrium value, the gas spring, throttle valve and proportional directional control valve can no longer be considered as linear, see Fig 3. To incorporate the non-linearity of these components their equations require some small changes. The change of the pressure and volume of gas depend on the volume of the fluid that displaced into, or withdraw from the gas spring according to adiabatic gas law as follows:

$$
\boldsymbol{P}_{g}^{\prime}=\boldsymbol{P}_{g s t} \frac{\left(\boldsymbol{V}_{g s t}\right)^{\gamma}}{\left(\boldsymbol{V}_{g s t}-\boldsymbol{V}_{g}^{\prime}\right)^{\gamma}}
$$

Considering equations (5) and (9), equation (4) can be rewritten as follows:

$$
\boldsymbol{P}_{s}^{\prime}=\boldsymbol{P}_{g s t} \frac{\left(V_{g s t}\right)^{\gamma}}{\left(V_{g s t}-V_{g}^{\prime}\right)^{\gamma}}+C_{1} \cdot Q_{D}^{2}
$$

Where $\left(V_{g}^{\prime}\right)$ is the volume compressed by the fluid displaced into the gas spring and is given by:

$$
\begin{aligned}
& V_{g}^{\prime}=-V_{\text {fluid }} \\
& V_{\text {fluid }}=A_{s t} \cdot\left(z_{W}-z_{b}\right)+V_{A}
\end{aligned}
$$

Where $\left(V_{A}\right)$ is fluid volume, which passes into the suspension system through the valve.

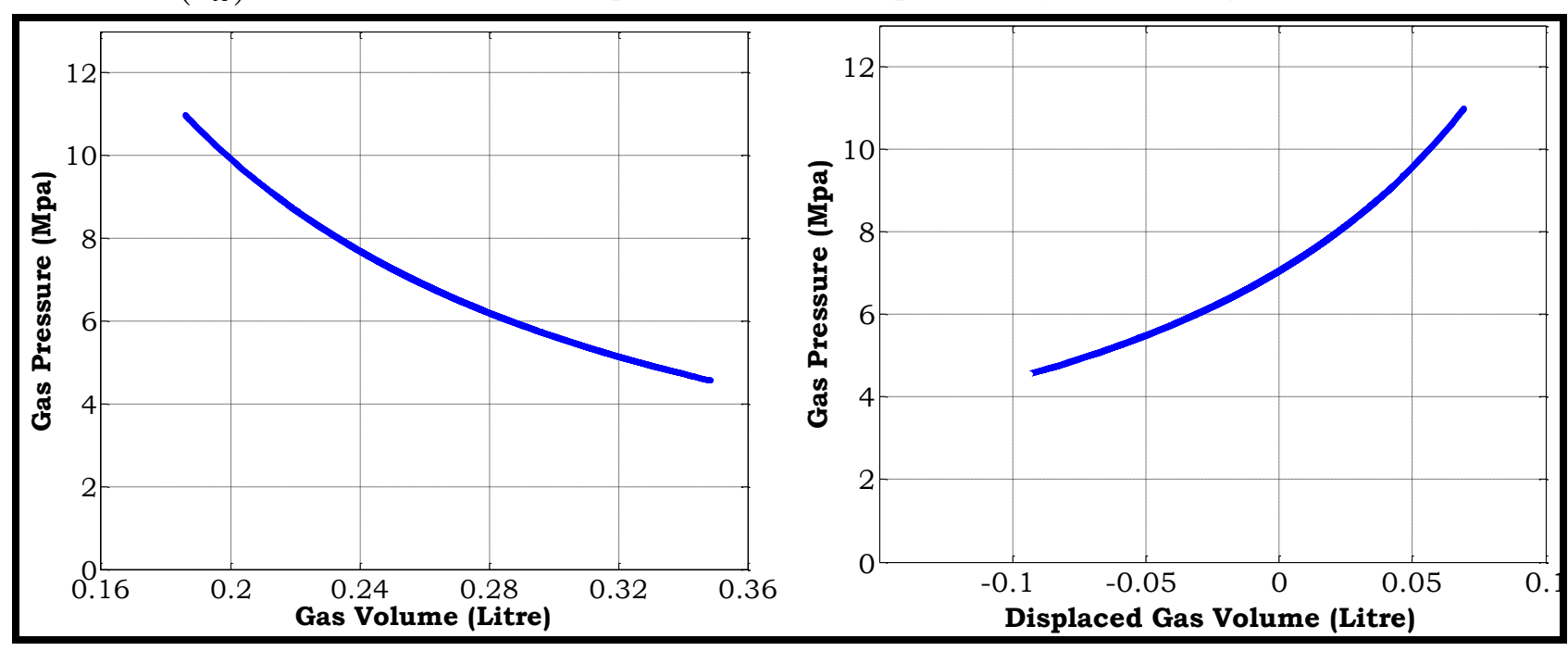

Fig. 3. Non-linear Characteristics for the Gas Spring [6] 
The pressure feedback signal $\left(e_{p}\right)$ is modified with respect to adiabatic pressure change as follow

$$
\boldsymbol{e}_{p}=\frac{\boldsymbol{P}_{g s t} \cdot\left(V_{g s t}\right)^{\gamma}}{\left(V_{g s t}-V_{g}^{\prime}\right)^{\gamma}}-\frac{P_{g s t} \cdot\left(V_{g s t}\right)^{\gamma}}{\left(\left(V_{g s t}-A_{s t} \cdot\left(z_{W}-z_{b}\right)\right)^{\gamma}\right.}
$$

The error is given by the following equation:

$$
\begin{aligned}
& \text { error }=P_{g d f}-K_{P f P} \cdot e_{P}-K_{P f D} \cdot \dot{e}_{P}[6] \\
& \dot{e}_{P}=\frac{\gamma P_{g s t}}{V_{g s t}} Q_{A}
\end{aligned}
$$

\subsection{Proportional Directional Control Valve}

The control valve is modeled using a standard relationship in which the flow rate $\left(Q_{A D}\right)$ is proportional to the pressure drop $\left(\Delta P_{V}\right)$ across the valve from supply to strut or from strut to atmosphere. Therefore, the valve supply voltage $\left(V_{V}^{\prime}\right)$ is given as follow:

$V_{V}^{\prime}=K_{P A} \cdot$ error

Accordingly, the demand flow rate $Q_{A D}$ is given as follows:

$Q_{A D}=0.1 \frac{K_{P V}}{R_{V}} \cdot\left(K_{P A} \cdot\right.$ error $) \cdot \sqrt{\Delta P_{V}} \quad$ [6]

$\Delta P_{V}$, is given in bar as follows:

$\Delta P_{V}=\left\{\begin{array}{l}\left(\left(P_{\text {susp }}\right)-P_{g}\right) \ldots \ldots \ldots \ldots \ldots . . . \text { if } \text { error }>0 \\ \left(P_{g}-P_{a t m}\right) \ldots \ldots \ldots \ldots \ldots . . \text { if } \text { error }<0\end{array}\right.$

The supply pressure used in this work $\left(P_{\text {susp }}=100\right.$ bar $)$ and according to the valve characteristics the maximum flow rate $\left(Q_{A \max }=25 \mathrm{~L} / \mathrm{min}\right)$ and $\left(K_{P V}=2.664 \times 10^{-10} \mathrm{~m}^{3} / \mathrm{sec} / \mathrm{Amp}\right)$.

$\mathrm{V}_{\mathrm{A}}$ is calculated according to the flow diagram shown in Fig. 4 and then used in equation (12).

It is a complicated task to calculate the feedback and feed/forward gains using the linear optimal control theory for this non-linear system. Therefore the system optimization based on the linear optimal control theory is carried out only for the linear system and the calculated feedback and feed/forward gains are used in both linear and non-linear cases. 


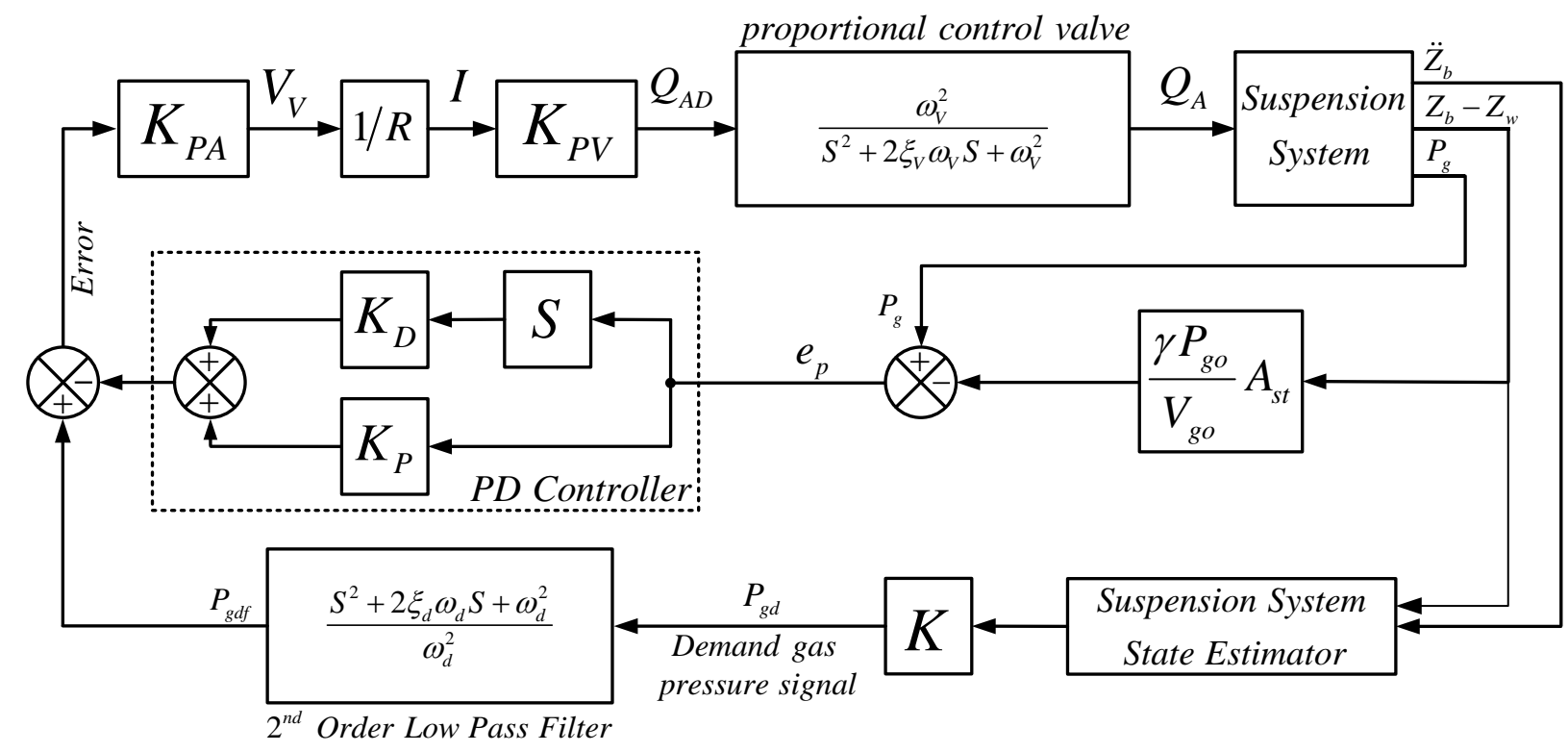

Fig. 4.Block-Diagram for the Slow-active Suspension System Controller

\section{Anti-lock Brake System Controller Design}

The detailed modelling work of the Anti-lock Brake System is presented by the authors in [14], for the purpose of completeness of this paper; the modelling work can be summarized as follows:

\subsection{The Longitudinal Dynamics}

Referring to Fig. 1, the tire vertical load $\left(F_{z}\right)$ is simply calculated as follow:

$F_{\text {Tire Vertical Load }}=\underbrace{\left(m_{b}+m_{w}\right) \cdot g}_{\text {Tire Static Load }}+\underbrace{m_{b} \cdot \ddot{z}_{b}+m_{w} \cdot \ddot{z}_{w}}_{\text {Tire Dynamic Load }}$

Also the following equations are derived:

$$
\begin{aligned}
& \ddot{x}_{b}=\frac{1}{m_{b}+m_{w}}\left(F_{x}-\frac{1}{2} \cdot \rho \cdot C_{d} \cdot A_{f} \cdot \dot{x}_{b}^{2}\right) \\
& \dot{\omega}=\frac{1}{J_{w}}\left[\left(F_{x}+F_{r}\right) \cdot R_{w}-T_{b}\right]
\end{aligned}
$$

The Pacejka's Magic Formula is used to estimate the barking force $\left(F_{x}\right)$ at the tire-ground contact patch, more details can be found in [14]. The formula relates the percentage of wheel skid ratio $(S)$ and tire vertical force $\left(F_{z}\right)$ as follows:

$$
\begin{aligned}
& S=\left(1-\frac{\omega \cdot R_{w}}{\dot{x}_{b}}\right) \times 100 \% \\
& F_{x}=D_{m} \cdot \sin \cdot\left[C_{m} \cdot \tan ^{-1}\left(B_{m} \cdot S-E_{m} \cdot\left(B_{m} \cdot S-\tan ^{-1}\left(B_{m} \cdot S\right)\right)\right)\right]
\end{aligned}
$$


Where: $\left(C_{m}\right)$ is a constant, $\left(B_{m}, D_{m}, E_{m}\right)$ are functions of the tire normal $\operatorname{load}\left(F_{z}\right)$ and slip [14].

The tire braking force versus skid ratio is simulated for the model with and without suspension as shown in Fig. 5. It is obvious that, the potential of fluctuating tire dynamic load and braking force accordingly is increased when the suspension system features are considered. This result conforms to the well-known fact that, the design of suspension system is highly affect the dynamics of forces at the tire ground contact area in both vertical and longitudinal directions. This effect should be carefully considered whenever the stability of the vehicle during braking maneuver is a prime of interest. On the other hand, it is expected that the ride comfort will be significantly affected in an adverse manner.

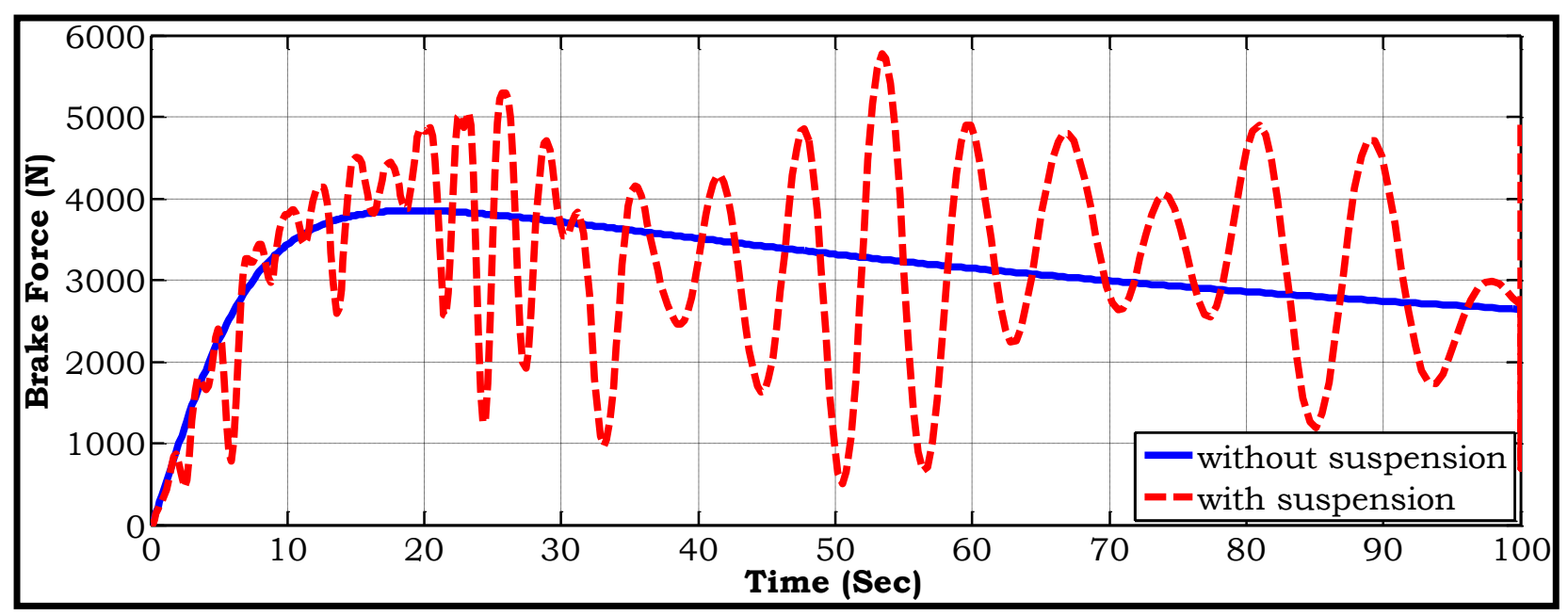

Fig. 5.The Dependency of the Generated Braking Forces on the Suspension System

\subsection{The ABS Controller}

The proposed control strategy combines a separate controller for the anti-lock brake system and a non-linear slow-active suspension system with a governing algorithm to coordinate the two controllers. Fig. 6 shows schematic drawings for the integrated control system comprising a slow-active controlled suspension and controlled ABS brake system.

The fundamental function of the ABS control system is to regulate the friction utilization at the tire-ground contact area during braking process [11, 12]. Accordingly, it prevents the tire from excessive skid particularly at higher braking forces. The tire skid ratio is limited by a desired value of $15 \%$ to maintain the peak braking force over different levels of road adhesion and tire vertical load. The estimated skid ratio is then compared with the value of the desired skid ratio to produce an error signal. For each value of the error, the controller returns 1 if the value is greater than zero and hence the pressure is increased, returns 0 if the error equals zero and hence the pressure remains unchanged, and -1 if it is less than zero, and hence the pressure is reduced. On the other hand, according to the signal of the vehicle speed, the suspension controller modifies the feedback gains to minimize the fluctuations of tire normal force. The angular speed of the tire, deceleration, vehicle speed and hydraulic pressure of the brake fluid are measured from several sensors in order to estimate the tire skid ratio.

According to the demand hydraulic pressure $\left(P_{d}\right)$, a proportional directional control valve is employed to modulate the hydraulic brake pressure $\left(P_{a}\right)$ as shown in Fig. 6. The directional control valve is modeled as a first order differential equation with a time delay $(t)$ as follows: 
$\dot{P}_{a}+\left(\frac{1}{t}\right) P_{a}=\left(\frac{1}{t}\right) P_{d}$

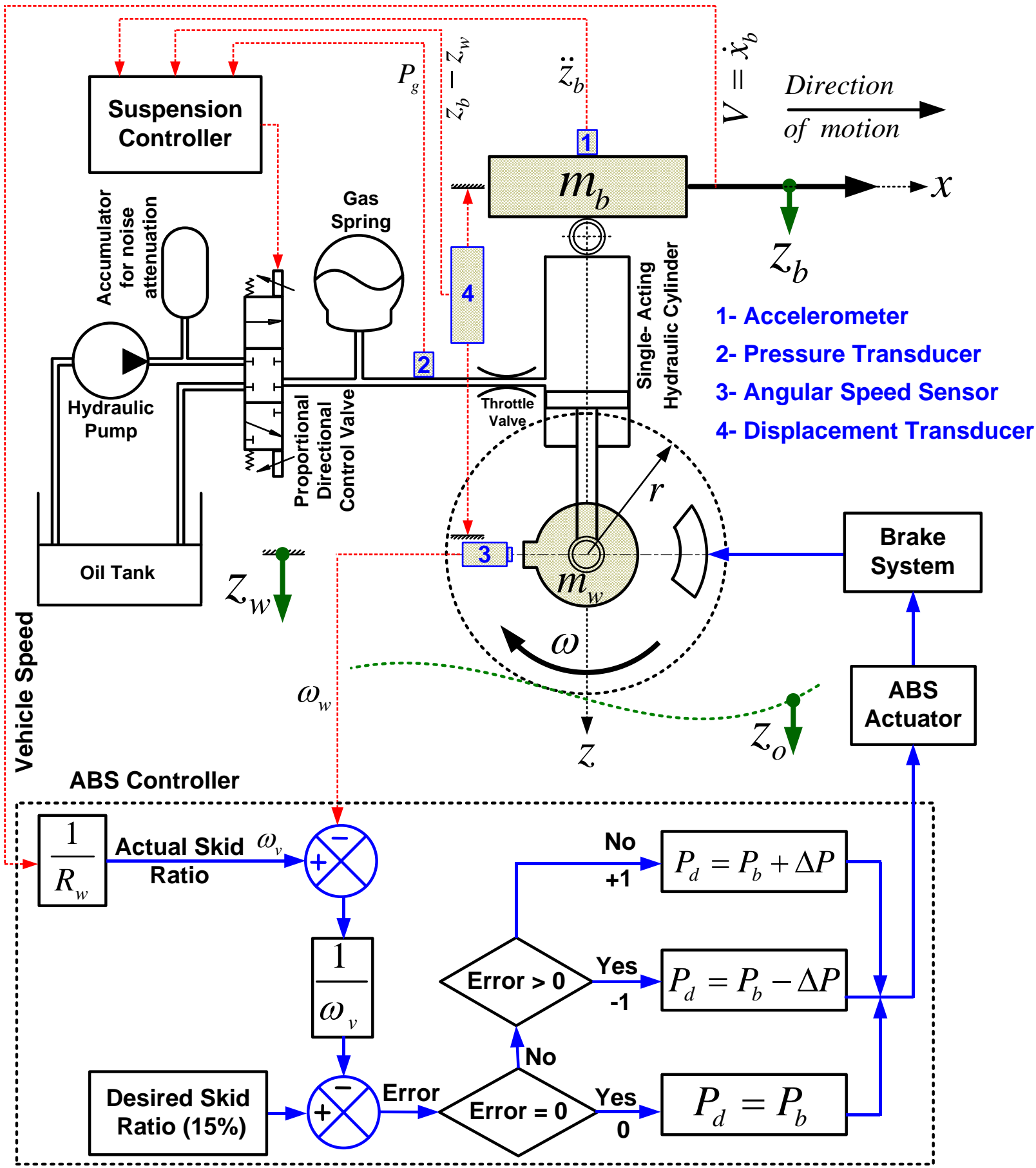

Fig. 6.Block Diagram for the ABS and Non-linear Slow-active Suspension Controllers

The resulting brake torque $\left(T_{b}\right)$ can be calculated as is a linear function of the brake pressure $\left(P_{a}\right)$, the area of the wheel cylinder $\left(A_{w c}\right)$, the disk brake lining friction coefficient $\left(\mu_{b}\right)$, the effective disk brake radius $(r)$ and the number of friction surface $\left(n_{S}\right)$ as follows:

$T_{b}=\underbrace{P_{a} \cdot A_{w c}}_{\text {Piston Force }} \cdot \mu_{b} \cdot n_{s} \cdot r$ 


\section{Road Profile}

It is widely recognized that the road surfaces approximate to Gaussian random processes, having a power spectral density (PSD) of the form:

$$
\operatorname{PSD}(f)=\frac{R_{c} V^{n-1}}{f^{n}}
$$

$R_{c}$ is the road roughness coefficient (see Table 1$), V$ is the vehicle speed $(\mathrm{m} / \mathrm{sec}), f$ is the road excitation frequency $(\mathrm{Hz}), n$ is an exponent with a recommended value of 2.5. The road input is represented as linear filtered white noise process by the following first order differential equation in time domain:

$\dot{z}_{o}=F_{W} \cdot z_{o}+B_{2} \cdot w(t)$

Where: $\left(F_{W}=-2 \pi \alpha V\right), B_{2}=1,(\alpha)$ is the cut-off frequency wave number $=0.005($ cycle $/ \mathrm{m})$, $(V)$ is the vehicle speed [6].

\section{Results and Analysis}

The derived integrated control algorithm as well as the proposed optimization technique is implemented using the MATLAB package. For the purpose of performance comparison, several simulation results have been reported incorporating Anti-Lock Braking system with passive suspension system and non-linear slow-active suspension system. For the braking performance evaluation, several measures are used such as the vehicle forward speed, the wheel rotational speed, the braking pressure, the tire skid ratio and finally the stopping distance. Other important results such as the effect of the road roughness coefficient and the coefficient of adhesion on the braking performance are also considered for both systems. In carrying out these calculations, the numerical values of the vehicle main parameters are used and given in Appendix (I).

The results of simulation are illustrated in Figs. 7-13. The initial speed of the vehicle is 100 $\mathrm{Km} / \mathrm{h}(27.8 \mathrm{~m} / \mathrm{s})$ and the brake pedal is applied while driving on a wet road with minor roughness coefficient $\left(R_{c}=50 \times 10^{-8}\right)$.

Primarily, Power spectral density results of body acceleration and DTL for the non-linear passive, linear slow-active and non-linear slow-active system are shown in Figs. 7-8, around the body resonance peak, the linear and non-linear systems behave very similarly to each other. The only slight difference appears to be above $9 \mathrm{~Hz}$ and this is almost certainly due to the different levels of effective damping between a linear value of $2000 \mathrm{Ns} / \mathrm{m}$ and throttle valve position 2.5 .

The result of implementing the integrated controller, ABS and non-linear slow-active suspension system, reveals an improved stopping time as shown in Figs. 9. The integrated controller monitors both vehicle and wheel rotational speed sensors at all times. Therefore, it regulates the braking pressure to the wheel cylinder up and down, Fig. 11, according to the desired skid ratio as shown in Fig. 10. As a result, the wheel is prevented to excessively lockup and thus decelerates at similar rate to the vehicle body. A comparison between the integrated system and the different suspension systems with ABS are indicated in terms of the stopping time and the stopping distance as shown in Table (1). 
Table (1) Comparison between Different Suspension Systems Integrated with ABS system

\begin{tabular}{|l|c|}
\hline Braking distance with Passive suspension system $(\mathrm{m})$ & $\mathbf{7 2}$ \\
\hline Braking distance with Linear slow-active suspension system $(\mathrm{m})$ & 68 \\
\hline Braking distance with Non-Linear slow- active suspension $(\mathrm{m})$ & 103 \\
\hline Braking distance with Non-Linear slow-active suspension & 95 \\
\hline
\end{tabular}

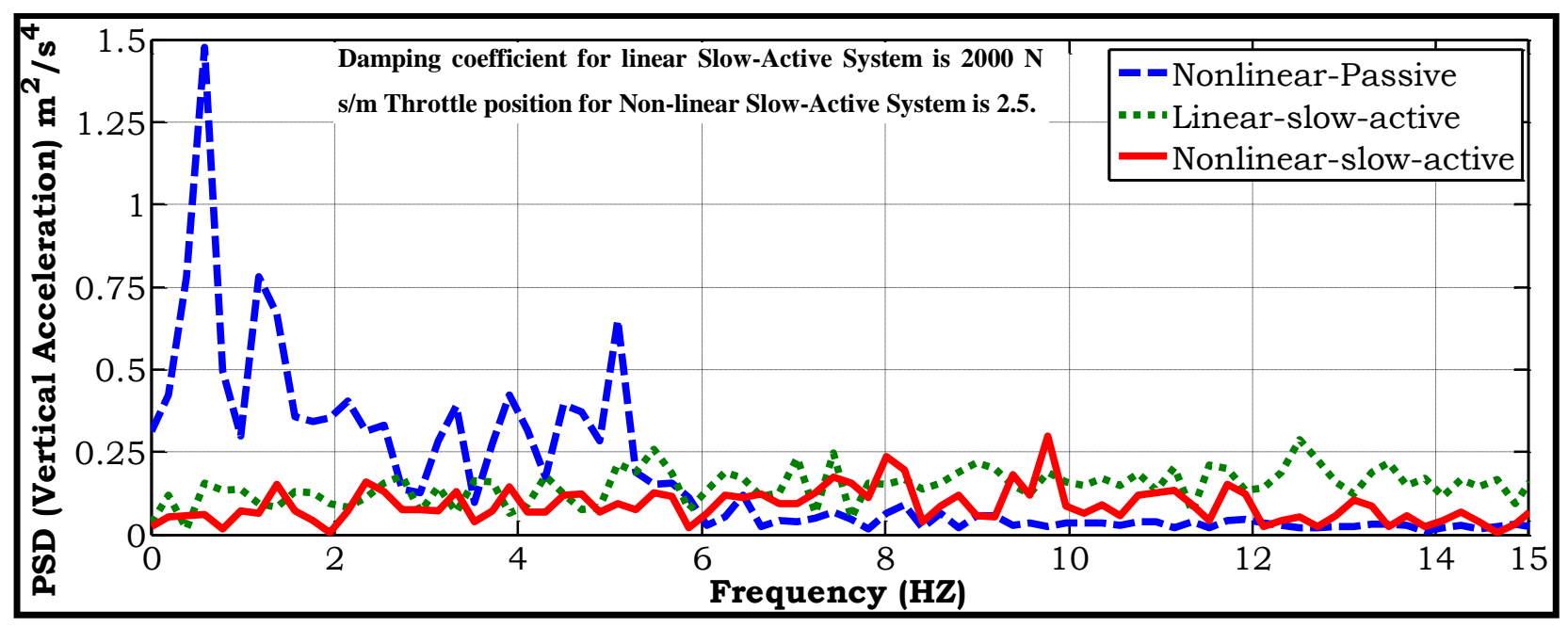

Fig. 7.PSD of Body Acceleration for Linear versus Nonlinear Slow-Active System

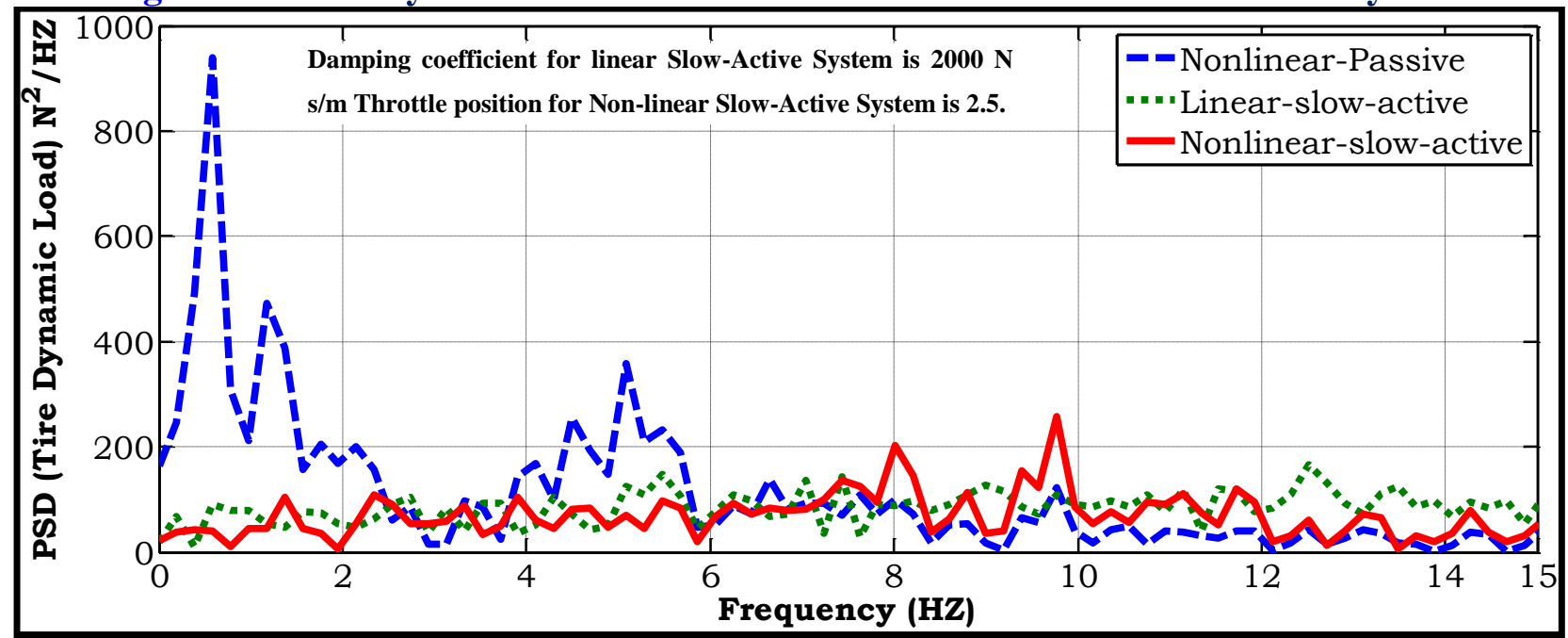

Fig. 8.PSD of Tire Dynamic Load for Linear versus Nonlinear Slow-Active System

To investigate the improvements afforded by the proposed system, Fig. 9illustrates the outcomes of implementing the integrated control system in comparison to a conventional ABS fitted with other suspended systems. The evaluation is carried out in terms of the stopping distances for all systems, it could be seen that the braking distance of different suspension systems is differs due to changing of dynamic tire load which lead to changing in normal force and from the beginning of this chapter the braking force is changing linearly with normal force and off course inversely with braking distance. The analysis of this figure shows that the nonlinear-passive suspension system is the highest braking distance and linear slow-active suspension system is the lowest one. 


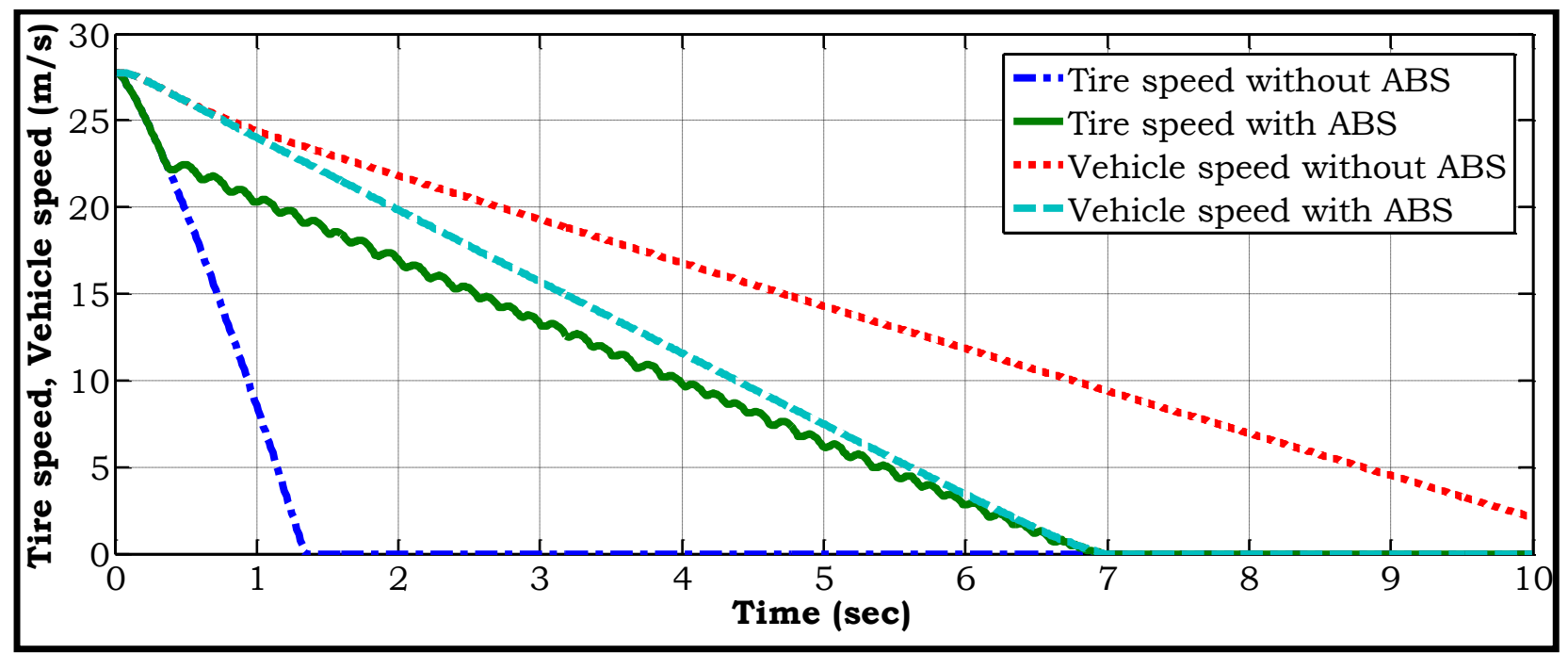

Fig. 9.Improvement of Braking Performance (Vehicle Speed) using ABS System

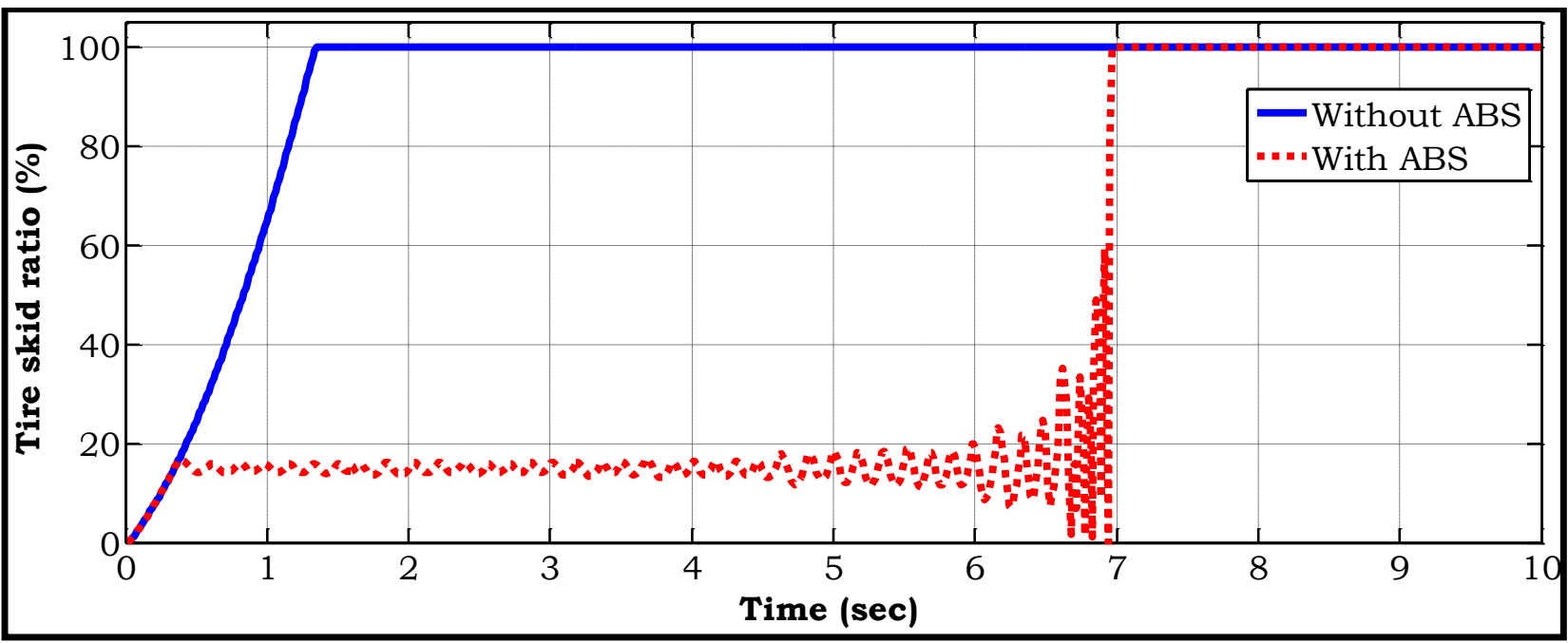

Fig. 10.Improvement of Braking Performance (Skid Percentage) using ABS System

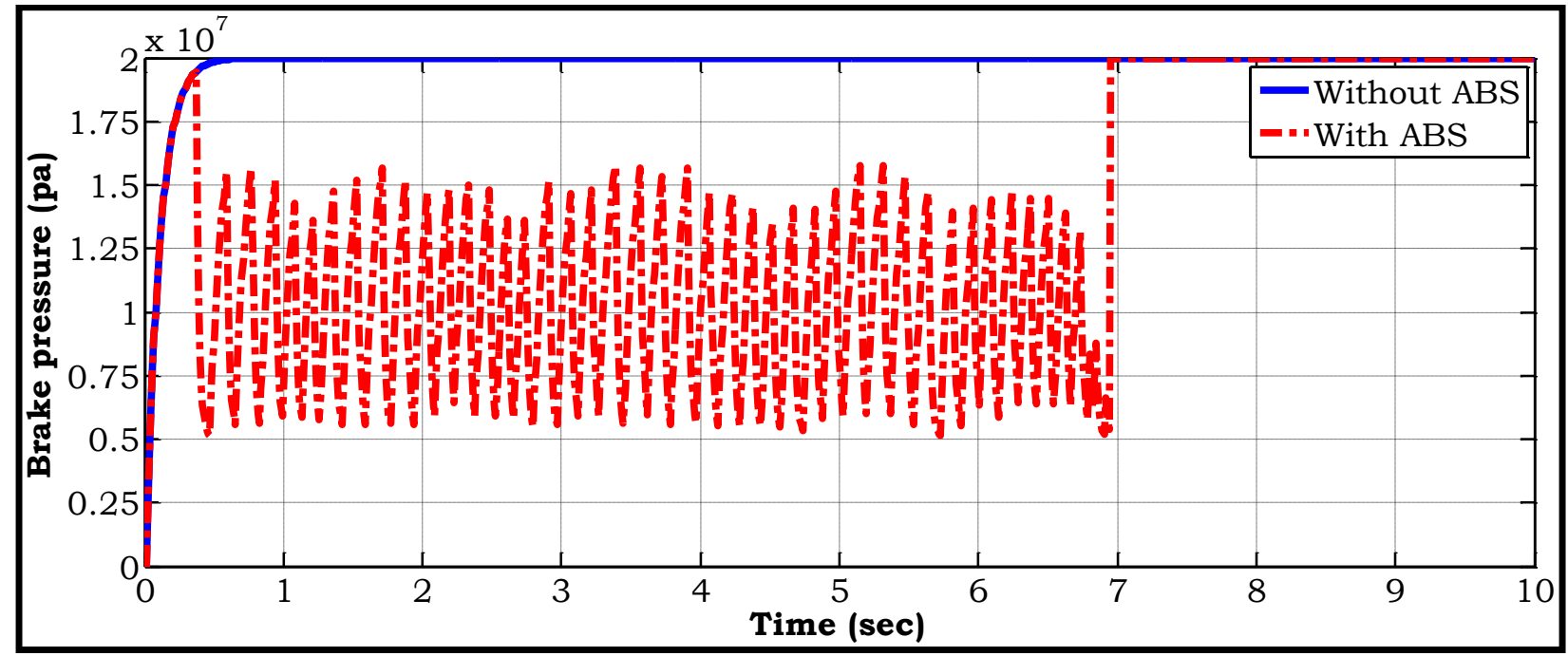

Fig. 11.Improvement of Braking Performance (Brake system pressure) using ABS System 


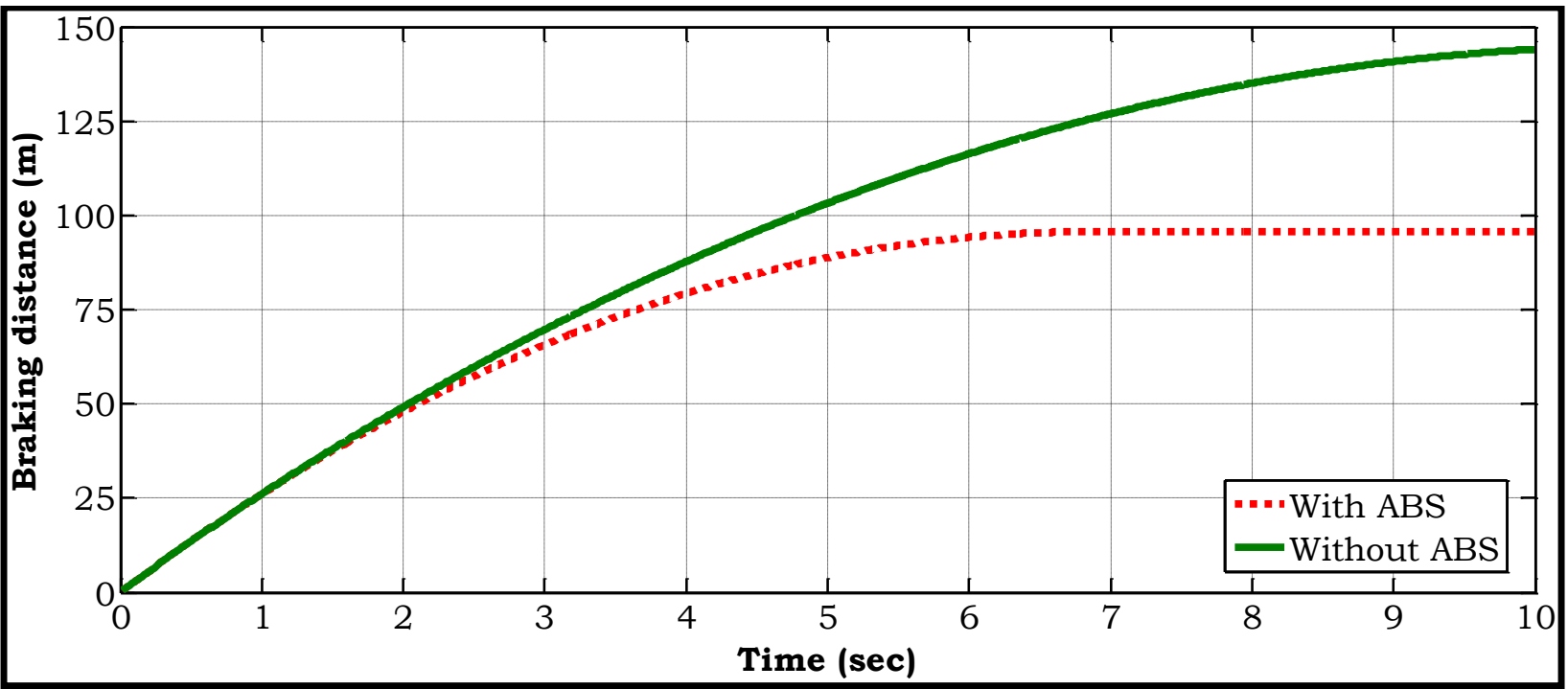

Fig. 12.Improvement of Braking Performance (Braking Distance) using ABS System

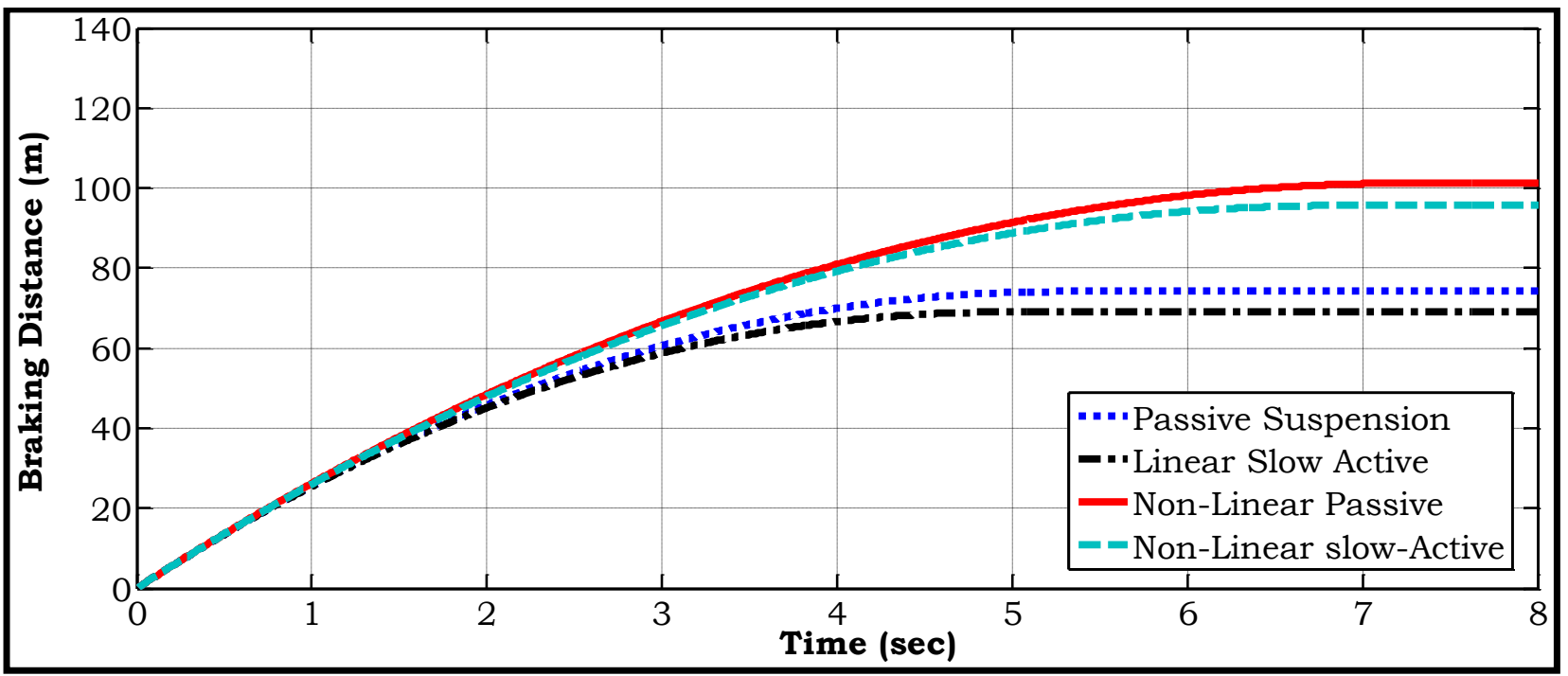

Fig. 13.Comparison of Braking Distance considering Different types of Suspension Systems

\section{Conclusions}

A nonlinear mathematical formulation for a quarter vehicle model has been derived to study the effect of non-linear components of slow-active suspension on both ride and braking dynamics. The coupling between both systems dynamics is arises from the dynamic normal load at the tire/terrain contact area. An integrated controller is designed to minimize the dynamic tire load and maximize the maximum tire/terrain brake force. For this purpose, two controllers, slow-active suspension controller and anti-lock braking system controller, are combined together to the so called integrated controller. It has been illustrated that, the integrated controller reduces the stopping distance on different terrain conditions considering the suspension system components nonlinearities. And, therefore improves the braking distance to avoid or reduce the impact of vehicle accident. The proposed controller is suitable for enhancing the vehicle mobility during traction by controlling the tire/road interaction forces and preventing the physical fatigue of the driver due to vehicle vibration. 


\section{References}

[1] J. Y. Wong "Theory of ground vehicles", $4^{\text {th }}$ ed., Hoboken, N.J., Wiley, 2008.

[2] S. Sulaiman, P. M. Samin, H. Jamaluddin, R. Abd Rahman, and M. S. Burhaumudin, "Ground hook Control of Semi-Active Suspension for Heavy Vehicle", International Journal of Research in Engineering and Technology (IJRET), Vo.1, No. 3, 2012.

[3] G. Koch, and T. Kloiber "Driving State Adaptive Control of an Active Vehicle Suspension system", IEEE Transactions on Control Systems Technology, Vol. 22, No. 1, 2014.

[4] C. Gohrle, A. Schindler, A. Wagner, and O. Sawodny "Design and Vehicle Implementation of Preview Active Suspension Controllers", IEEE Transactions on Control Systems Technology, Vol. 22, No. 3, 2014.

[5] B. Gao, J. Darling, DG. Tilly, RA. Williams, A. Bean, and J. Donahue "Control of a Hydropneumatic active Suspension Based on a non-linear Quarter-Car Model", Proceedings of the Institution of Mechanical Engineers, Part I-Journal of Systems and Control Engineering", Vol. 220, pp.15-31, 2006.

[6] El-Demerdash, S.M. and Crolla, D.A. "Effect of non-linear components on the performance of a hydro-pneumatic slow-active suspension system", Proceedings of the Institution of Mechanical Engineers, Part D: Journal of Automobile Engineering, 1996.

[7] J. Fen, S. Zheng, and F. Yu "Bandwidth-Limited Active Suspension Controller for an Off-Road Vehicle Based on Co-Simulation Technology", Mech. Eng. China, 3(1), pp. 111-117, 2008.

[8] M. Sibielak, J. Konieczny, J. Kowal, W. Raczka, and D. Marszalik, "Optimal Control of Slow-Active Vehicle Suspension - Results of Experimental Data", Journal of Low Frequency Noise Vibration and Active Control, Vol. 32, pp. 99-116, 2013.

[9] MM. ElMadany "Control and Evaluation of Slow-Active Suspension with Preview for a Full Car", Mathematical Problems in Engineering, No. 375080, 2012.

[10] SF. Van der Westhuizen, and PS. Els "Slow Active Suspension Control for Rollover Prevention", Journal of Terramechanics, Vol. 50, pp. 29-36, 2013.

[11] Nilanjan Patra, Kalyankumar Datta,"Sliding mode Controller for Wheel-slip Control of Anti-lock Braking System", IEEE International Conference on Advanced Communication Control and Computing Technologies (ICACCCT) 2012.

[12] Ayman A. Aly, El-Shafei Zeidan, Ahmed Hamed, Farhan Salem, "An Antilock-Braking Systems (ABS) Control: A Technical Review", Intelligent Control and Automation, 2011, 2, 186-195 doi:10.4236/ica.2011.

[13] S.M. El-Demerdash, M.B. Abdelhady, M.A. AlNashar and A.S. Emam, "Effect of Vehicle Suspension Control on the Performance of Anti-Lock Brake Systems", IMechE International Conference on Braking Technology, St William's College, York, May 7-9, 2006, UK. 
[14] A.M. Onsy, A.M. Sharaf, M.M. Ashry and S.M. Eldemerdash "Effect of Slow-Active Suspension Controller Design on the Performance of Anti-lock Brake System", 15 International Conference on ASAT- 15, Military Technical College, Kobry Elkobbah, Cairo, Egypt, 2013.

[15] J. Song "Development and Comparison of Integrated Dynamics Control Systems with Fuzzy Logic Control and Sliding Mode Control", Journal of Mechanical Science and Technology, Vol. 27(6), pp. 1853-1861, 2013.

\section{Appendix (I) Main parameters of the quarter vehicle model and the ABS}

\begin{tabular}{|l|c|l|l|}
\hline \multicolumn{1}{|c|}{ Parameter } & Symbol & \multicolumn{1}{|c|}{ Value } & \multicolumn{1}{c|}{ Unit } \\
\hline Quarter of the vehicle body or sprung mass & $m_{b}$ & 578 & {$[\mathrm{~kg}]$} \\
\hline Unsprung masses & $m_{w}$ & 58.25 & {$[\mathrm{~kg}]$} \\
\hline Engine and wheel moments of inertia & $J_{w}$ & 13.7 & {$\left[\mathrm{kgm}^{2}\right]$} \\
\hline Passive spring stiffness coefficients & $K_{s}$ & 25 & {$[\mathrm{kN} / \mathrm{m}]$} \\
\hline Passive damping coefficients & $C_{s}$ & 1 & {$[\mathrm{kNs} / \mathrm{m}]$} \\
\hline Tire vertical stiffness coefficients & $K_{t}$ & 255 & {$[\mathrm{kN} / \mathrm{m}]$} \\
\hline Vehicle aerodynamic frontal area & $A_{f}$ & 2.04 & {$\left[\mathrm{~m}^{2}\right]$} \\
\hline Vehicle aerodynamic drag coefficient & $C_{d}$ & 0.539 & {$[--]$} \\
\hline Wheel cylinder piston radius & $r_{p}$ & 0.0185 & {$[\mathrm{~m}]$} \\
\hline Tire dynamic radius & $R_{w}$ & 0.273 & {$[\mathrm{~m}]$} \\
\hline Front and rear lining coefficient of friction & $\mu_{b}$ & 0.35 & {$[--]$} \\
\hline
\end{tabular}

